\title{
Synthesis of carbon nanotubes using green plant extract as catalyst: unconventional concept and its realization
}

\author{
Nishant Tripathi ${ }^{1,2} \cdot$ Vladimir Pavelyev $^{2} \cdot$ S. S. Islam ${ }^{1}$
}

Received: 8 August 2017/ Accepted: 11 September 2017/Published online: 16 September 2017

(c) The Author(s) 2017. This article is an open access publication

\begin{abstract}
Green catalyst derived from plants, a cheap and abundant natural source, is used for the synthesis of multiwalled carbon nanotubes (MWNTs). The concept is unconventional and practically realized into existence by simple CVD growth while keeping away the potential hazards caused by metal catalyst on environment and living organisms. The notable points to mention of such growth are: (1) grown CNTs are free from toxic metal catalyst, (2) low growth temperature $\left(575^{\circ} \mathrm{C}\right)$ required and produced high yield vis-à-vis any other catalyst used so far reported, and (3) no need of expensive and complex systems for its synthesis. Besides, growth of SWNT as well as carbon nano-belts with hollow rectangular cross-section is observed when growth temperature increased to $800{ }^{\circ} \mathrm{C}$, specifically, for the wall-nut extract. The samples were characterized by microscopic and spectroscopic analysis and the results verified our study. The present work provides innovative technique and may open up new avenues for CNTs synthesis and its applications.
\end{abstract}

Keywords Green catalyst - Low temperature growth . CNTs $\cdot$ CNBs

S. S. Islam

sislam@jmi.ac.in

1 Centre for Nanoscience and Nanotechnology, Jamia Millia Islamia (A Central University), Jamia Nagar, New Delhi 110025, India

2 Department of Nanoengineering, Samara National Research University, 34, Moskovskoye Shosse, Samara, Russia 443086

\section{Introduction}

Since the discovery of carbon nanotubes in 1990 (Iijima 1991), CNTs trigger the real field of nanotechnology due its remarkable physical and chemical properties. Many researcher start works on nanomaterial-based application (Singh et al. 2017; Sharma et al. 2017; Sharma and Gupta 2016) and CNTs attracted intense interest in the scientific community as well as industry. However, these properties are predicted for ideal CNTs which are unlike from the CNTs we are practically developing nowadays. In spite of a wide development in CNT research and its applications over more than two decades, still we are incapable to develop CNTs with the well-defined properties through cost-effective technique. The inappropriate knowledge of CNT growth mechanism (Tripathi et al. 2014a, b) is the main cause of this problem. It is not even clearly understood whether inorganic catalyst, a carcinogenic and harmful component is essential for CNTs' growth where high yield is also an important factor. Moreover, devices made of CNTs grown using metal catalyst pose serious impediments in its commercialization, as numerous reports to flag potential dangers of nanotubes in places at manufacturing, disposal and application sites (Buzea et al. 2007). Therefore, there is an immediate need to examine its negative aspects until it becomes too late. The great benefits of using nanomaterials such as CNTs in modern technologies were no longer questioned under the assumption that they are not dangerous than graphite. It is reported that the metal catalysts used for CNTs' growth harbor serious threat to living organisms (Panyala et al. 2008). The catalyst particles usually remain in the grown CNTs, and these can be inserted in human body in medical application (Panyala et al. 2008). Similar problem is associated with CNTs used for textile industry. In the field 
of agriculture, metal catalyst particles in CNTs may enter in plants and can cause misalignment of chromosomes at metaphase plate resulting in cell division inhibition (Masarovicova and Kralova 2013). Nano-sized metal catalyst is also not adaptable with semiconductor-based devices as it reduces quantum efficiency in photo-detectors (Liu et al. 2009), and device lifetime (Luc and Bruno 2010). At high temperature, metal catalyst particle melts or vaporizes and attach on the CNT wall; thus occupy more surface area and block lattice vibration of CNTs which disturb lattice wave propagations, a key factor in temperature sensor (Liu et al. 2013). Another important issue is the production cost of CNTs, where the instruments needed for CNTs' growth are not only expensive but the temperature requirement for CNTs' growth is also very high, i.e., around $700-1200{ }^{\circ} \mathrm{C}$ depending on the choice of metal catalyst and type of CVD (Tripathi et al. 2015; Liu et al. 2008; Tripathi et al. 2015; Tripathi et al. 2014c). Under
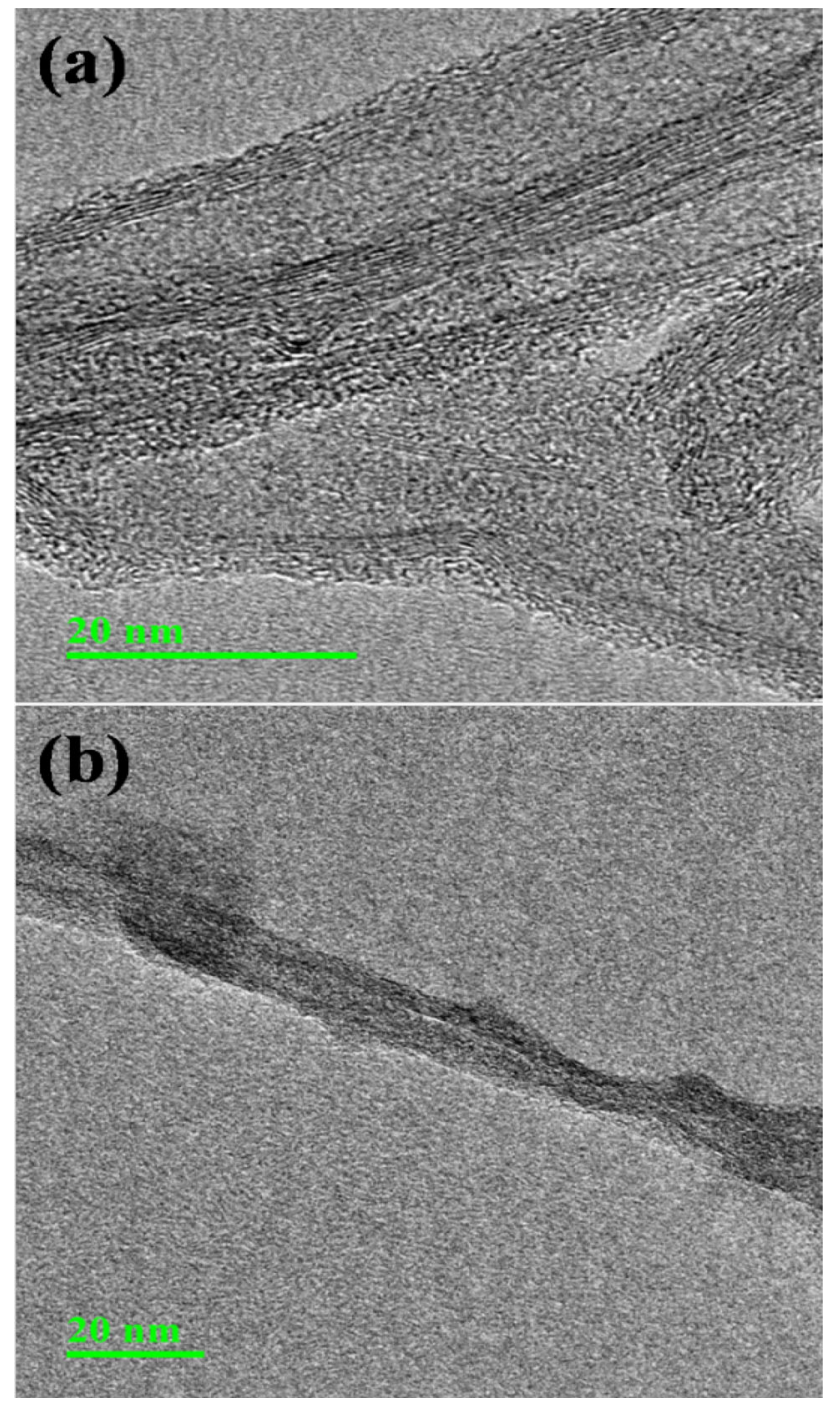

Fig. 1 HRTEM images of grown CNTs yield from walnut extract such circumstances, development of a non-metallic cheap catalyst is required for the commercialization of CNTs in medical, textile, agriculture and electronics field.

Moreover, many reports are published on CNT growth using non-metal catalysts (Tripathi et al. 2014a). Merits and demerits are many; even bulk production and toxicity are still a major concern (Bellucci 2009). In such scenario, green catalyst-assisted CNTs' growth may come as a rescue to overcome the threats as discussed so far. At a glance, the merits of green catalyst are:

- It is non-toxic in nature,

- green catalysts are organic compounds and it provides CNTs free from metal impurities.

- Metal catalyst particle sources are limited while green catalysts are abundant in nature.

- Metal catalysts are very costly while green catalysts can be available at almost zero cost.

- Use of green catalyst finishes the requirement of sputtering, dip coating type costly equipment.

- Green catalyst reduces CNTs' growth temperature up to $575^{\circ} \mathrm{C}$ and hence reduces the power consumption.

- Clean room is not required for CNTs' growth as green catalyst is non-toxic in nature, and

- green catalyst is easy to make; therefore, it reduces the complexity in growth process.

In this paper, an unconventional concept and demonstration for green catalyst-assisted bulk CNTs' growth have been successfully presented. CNTs have been grown using green catalyst synthesized from garden grass (Cynodon dactylon), rose (Rosa), neem (Azadirachta indica) and wall-nut (Juglans regia) plant extracts. The CNT's growth, in case of wall-nut extract, is achieved at CVD temperature $575{ }^{\circ} \mathrm{C}$, and the yield is enormously high vis-à-vis the other extracts. While increasing its growth temperature to $800{ }^{\circ} \mathrm{C}$, growth of carbon nano-belts (CNBs) was observed, and has been confirmed by high resolution electron microscopes, Raman and IR spectroscopic studies. To the best of our knowledge, growth of such types of carbon derivatives using plant extracts is not so far reported. An in-depth understanding about the growth of nanoribbon is needed.

\section{Experiment}

Plant extract and its synthesis is carried out in a series of steps prior the growth of carbon derivates on substrate, and the steps are as follows: 

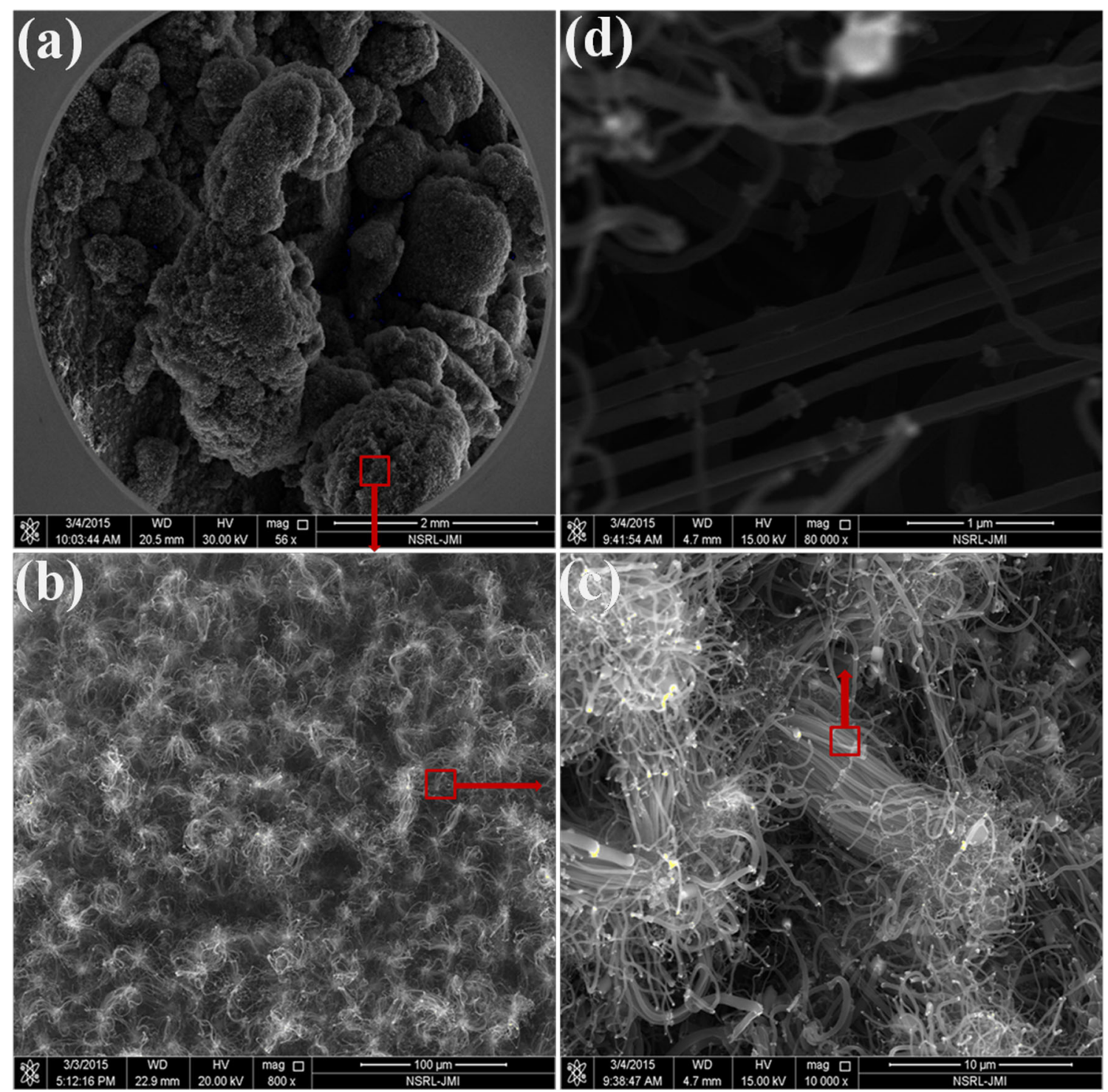

Fig. 2 FESEM images (a). b-d Magnified version on different spots marked by red arrows

\section{Process of plant extraction}

Green leaves of garden grass ( $C$. dactylon), rose (Rosa), neem (A. indica), Kaner (Thevetia peruviana), and walnut (J. regia) were used to draw the extract. Raw leaves were first washed thoroughly in DI water and then dried. The dried leaves were crushed by grinder to make powder and placed in a thimble which was kept in a Soxhlet apparatus. In a flask, methanol and extracting solvent were heated. And its vapors condense in condenser. The condensed extract dipped into the thimble. When the level of liquid in the chamber rises to the top of siphon tube, the liquid contents of chamber siphon into flask. This process continued till a drop of solvent from the siphon tube left leave residue when evaporated (Redfern et al. 2014).

\section{Sample preparation}

$0.5 \mathrm{gm}$ of each extract was dissolved in $50 \mathrm{ml}$ of methanol. The solution was kept in ultrasonicator for $30 \mathrm{~min}$. A drop of solution was dropped on an oxygen plasma cleaned p-type silicon substrate $(10 \times 10 \mathrm{~mm})$ through a micro pipette. Sample was dried in argon atmosphere.

\section{CVD process}

Prepared silicon sample was loaded in a thermal CVD. Heater of CVD system was switched on with temperature increasing rate $700{ }^{\circ} \mathrm{C} / \mathrm{h}$. At the first instance, we have tested walnut extract; the sample was heated from room temperature to $575{ }^{\circ} \mathrm{C}$ in the $50 \mathrm{sccm}$ continuous flow of argon gas. When temperature of furnace reached to $575{ }^{\circ} \mathrm{C}$, 


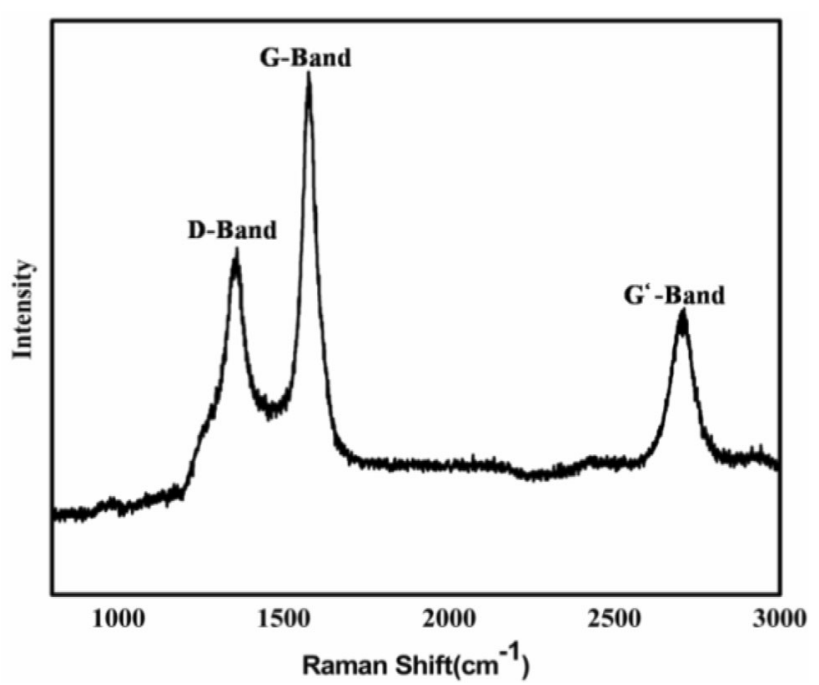

Fig. 3 Raman spectra of grown MWNTs

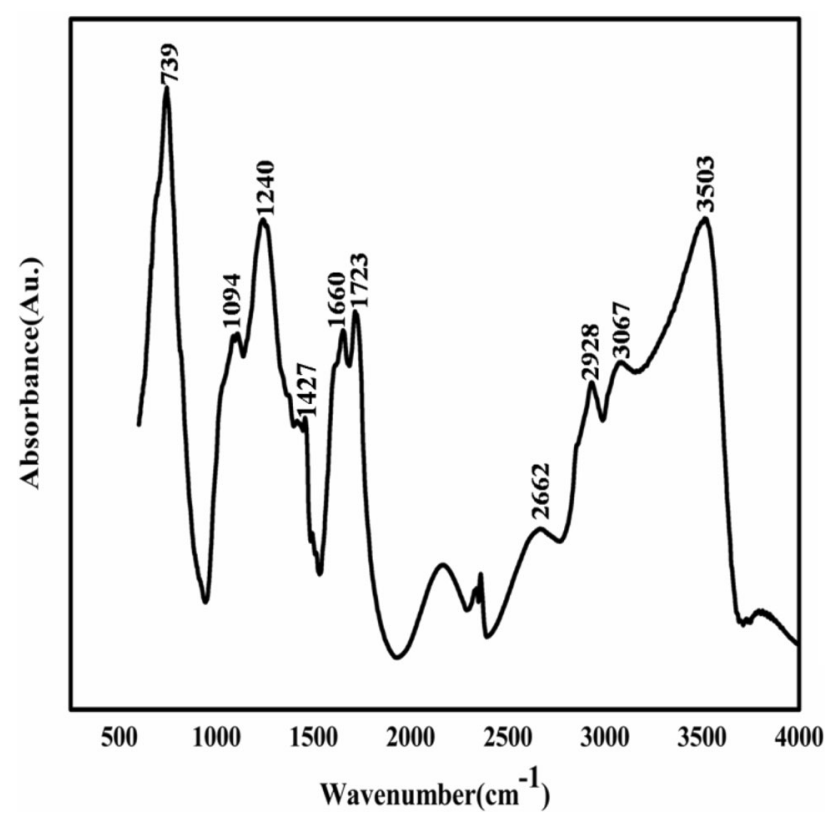

Fig. 4 FTIR spectra of walnut plant extract

acetylene gas with $15 \mathrm{sccm}$ flow was added with $50 \mathrm{sccm}$ argon gas for $10 \mathrm{~min}$. After $10 \mathrm{~min}$, flow of acetylene was stopped. Heater of CVD was then switched off. Flow of argon was continued till the temperature reaches to room temperature. When CVD cooled down to room temperature, sample was unloaded for characterization. The same procedure was adopted for other extracts and the growth temperature for all the extracts maintained at $575{ }^{\circ} \mathrm{C}$.

We measured the yield by high resolution scanning electron microscope (FESEM, NOVA NANOSEM 450), EDS (Bruker), HRTEM (TEM, FEI Tecani F20), FTIR (Vertex $70 \mathrm{~V}$, Bruker Optik) and micro-Raman spectrometer (LabRAM HR800, JY) with $488 \mathrm{~nm} \mathrm{Ar}^{+}$laser.

\section{Results and discussion}

Figure 1 shows HRTEM image of grown yield from walnut extract; the growth of MWNTs of diameter in the range of $8-15 \mathrm{~nm}$, ultra long length $(3600 \mu \mathrm{m})$, and high density on silicon substrate were observed. Figure 2a shows FESEM images. Figure $2 b-d$ shows its magnified version on different spots marked by red arrows. These images demonstrate the formation of ultra-dense network of CNTs and its alignment. On some spots the grown CNTs are vertically aligned, whereas on some other spots the alignment is horizontal. Further, the CNT yield was also calculated with a high precision electronic weighing balance (Wensar Mab 220) taking into account the pre- and post-growth weights of samples. The yield was around $0.0113 \mathrm{gm}$ and it is much higher than yields so far reported for any other catalyst. Figure 3 shows the Raman spectra of grown MWNTs where characteristic D-band $\left(1339 \mathrm{~cm}^{-1}\right)$ and G-band $\left(1583 \mathrm{~cm}^{-1}\right)$ confirm its existence, where D-band presents structural defects while G-band shows the graphitic structural quality of CNTs. In our case, small value of D- to G-band intensity ratio $\left(I_{\mathrm{D}} / I_{\mathrm{G}}\right)$, i.e., 0.59 supports the CNT growth of good structural quality and it is in commensurate with the HRTEM results shown in Fig. 1. To figure out growth mechanism of such metal catalyst-free CNTs, FTIR as well as EDS study were carried out on the samples for pre- and post-growth of CNTs. To mention that 'pre' stands for only synthesized extract made before loading it in CVD. The FTIR investigation of plant extract (walnut) and grown MWNTs is shown in Fig. 4. The spectra of plant extract shows important peaks at 739, 1094, 1240, 1427 ${ }^{1}$, 1660, 1723, 2662, 2928, 3067 and $3503 \mathrm{~cm}^{-1}$. The peaks from post-CNT growth sample (Fig. 5) observed at 615, $764,1080,1220,1381,1481,1620,1640,1660,1680$, 1724,1771 and $2400 \mathrm{~cm}^{-1}$. Tables 1,2 show the assignment of the modes obtained in both the cases. In both, preand post-growth FTIR spectra of sample, no metal compound exists. So it is the evidence of metal-free CNT growth.

To understand the reason behind such unexpected growth of CNTs, it become necessary to know the physical condition of green catalyst after heating at $575{ }^{\circ} \mathrm{C}$ temperature in argon atmosphere. For that we cooled down CVD system to room temperature without CNTs' growth. When sample was investigated by FESEM then we observed porous structure of carbon (see Fig. 6). Plant extract converted into porous or activated carbon. These pores of activated carbon provide the nucleation sites for CNTs' growth. And due to porous surface, activated carbon have large surface area as compared to transition metal, so nucleation sites for CNTs' growth is also in large number. This is the valid reason for ultra-dense CNTs' growth. It is 
Fig. 5 Post-CNT growth FTIR spectra

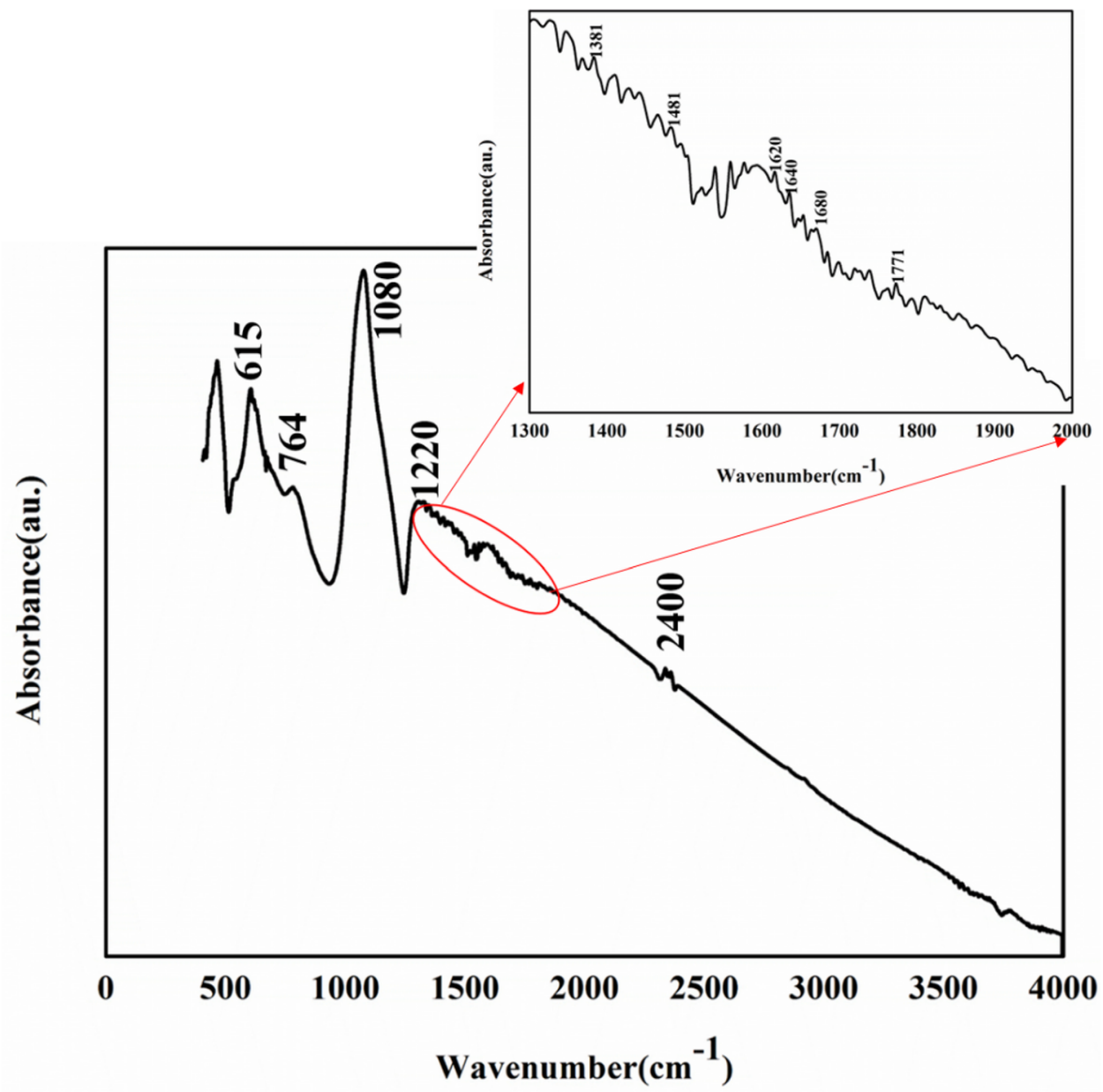

Table 1 FTIR analysis of walnut plant extract before CNT growth

\begin{tabular}{|c|c|c|c|}
\hline $\begin{array}{l}\text { S. } \\
\text { no. }\end{array}$ & $\operatorname{Peak}(\mathrm{s})\left(\mathrm{cm}^{-1}\right)$ & $\begin{array}{l}\text { Vibrational band } \\
\text { or compound } \\
\text { assignment }\end{array}$ & References \\
\hline 1 & 1427 and 1240 & $\mathrm{SiCH}_{2}$ & $\begin{array}{l}\text { Ramamurty and } \\
\text { Kannan (2007); } \\
\text { Silverstein et al. (1962); } \\
\text { Uthayakumar and } \\
\text { Sivasubramanian (2013) }\end{array}$ \\
\hline 2 & 729 and 1240 & $-\mathrm{CH}_{2} \mathrm{Cl}$ & $\begin{array}{l}\text { Ramamurty and } \\
\text { Kannan (2007); } \\
\text { Silverstein et al. (1962); } \\
\text { Uthayakumar and } \\
\text { Sivasubramanian (2013) }\end{array}$ \\
\hline 3 & 1660 and 1724 & $\begin{array}{l}\mathrm{C}=\mathrm{C}, \text { chain } \\
\text { compound }\end{array}$ & $\begin{array}{l}\text { Ramamurty and } \\
\text { Kannan (2007); } \\
\text { Silverstein et al. (1962); } \\
\text { Uthayakumar and } \\
\text { Sivasubramanian (2013) }\end{array}$ \\
\hline 4 & 1095 & $\mathrm{C}-\mathrm{O}$ & $\begin{array}{l}\text { Ramamurty and } \\
\text { Kannan (2007); } \\
\text { Silverstein et al. (1962); } \\
\text { Uthayakumar and } \\
\text { Sivasubramanian (2013) }\end{array}$ \\
\hline
\end{tabular}

Table 2 FTIR analysis of post-CNT growth

\begin{tabular}{|c|c|c|c|}
\hline $\begin{array}{l}\text { S. } \\
\text { no. }\end{array}$ & $\operatorname{Peak}(\mathrm{s})\left(\mathrm{cm}^{-1}\right)$ & $\begin{array}{l}\text { Vibrational band or } \\
\text { compound } \\
\text { assignment }\end{array}$ & References \\
\hline 1 & $\begin{array}{l}615,1080 \text { and } \\
1480\end{array}$ & $\mathrm{SiC}_{6} \mathrm{H}_{5}$ & $\begin{array}{l}\text { Ramamurty and Kannan (2007); } \\
\text { Silverstein et al. (1962); } \\
\text { Uthayakumar and } \\
\text { Sivasubramanian (2013) }\end{array}$ \\
\hline 2 & 1080 & $\mathrm{C}-\mathrm{CO}-\mathrm{O}-\mathrm{CO}-\mathrm{C}$ & $\begin{array}{l}\text { Ramamurty and Kannan (2007); } \\
\text { Silverstein et al. (1962); } \\
\text { Uthayakumar and } \\
\text { Sivasubramanian (2013) }\end{array}$ \\
\hline 3 & 1771 & $\mathrm{C}=\mathrm{O}$ & $\begin{array}{l}\text { Ramamurty and Kannan (2007); } \\
\text { Silverstein et al. (1962); } \\
\text { Uthayakumar and } \\
\text { Sivasubramanian (2013) }\end{array}$ \\
\hline 4 & 1210 & $\mathrm{O}-\mathrm{C}=\mathrm{C}$ & $\begin{array}{l}\text { Ramamurty and Kannan (2007); } \\
\text { Silverstein et al. (1962); } \\
\text { Uthayakumar and } \\
\text { Sivasubramanian (2013) }\end{array}$ \\
\hline 5 & 1381 & $\mathrm{C}-\mathrm{H}$ & $\begin{array}{l}\text { Ramamurty and Kannan (2007); } \\
\text { Silverstein et al. (1962); } \\
\text { Uthayakumar and } \\
\text { Sivasubramanian (2013) }\end{array}$ \\
\hline 6 & 1600 and 1700 & $\begin{aligned} \mathrm{C}=\mathrm{C}-\mathrm{C}=\mathrm{C} \text { and } \\
\\
\text { carbon chain } \\
\text { compound }\end{aligned}$ & $\begin{array}{l}\text { Ramamurty and Kannan (2007); } \\
\text { Silverstein et al. (1962); } \\
\text { Uthayakumar and } \\
\text { Sivasubramanian (2013) }\end{array}$ \\
\hline
\end{tabular}




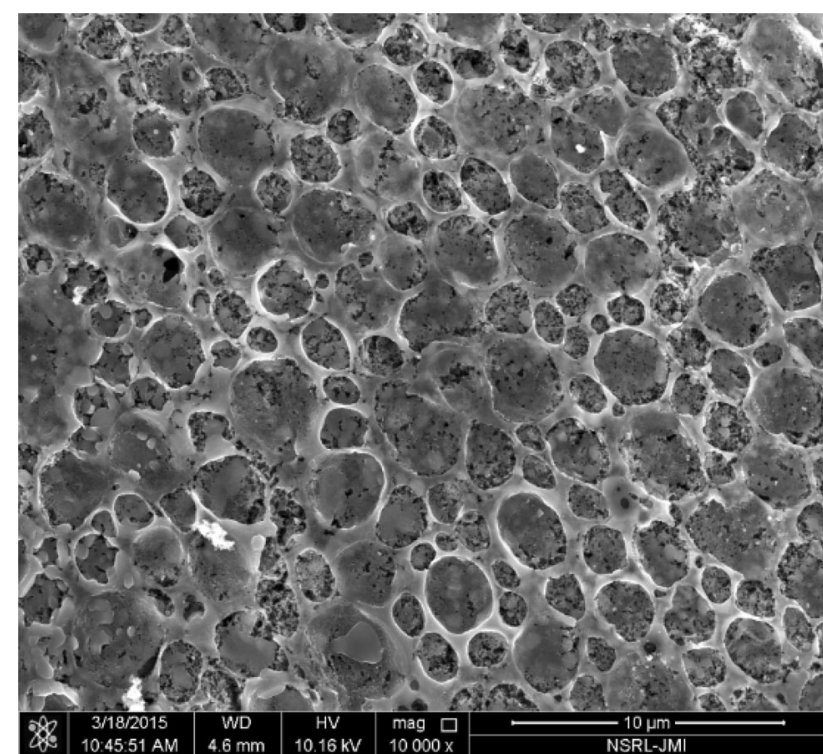

Fig. 6 FESEM image for porous carbon also well-known fact that activated carbon supports the decomposition of hydrocarbon at lower temperature (Silverstein et al. 1962). So, activated carbon plays an efficient role as catalyst for CNTs' growth. Since activated carbon have potential to decompose the hydrocarbon at lower temperature around $450{ }^{\circ} \mathrm{C}$ (Ramamurty and Kannan 2007). This is the reason that growth of CNTs with plant extract takes place at very low temperature. Another noticeable point is that activated carbon also have ability to absorb hydrocarbon (Silverstein et al. 1962) leading to more acetylene decomposition. As a result, more carbon atoms attach to activated carbon to nucleate the CNTs. This is also valid reason for ultra-dense growth of CNTs. Carbon element is known for its catenation property and for forming long chain. Therefore, once the carbon atoms attached to the surface of newly activated carbon, inserted carbons keep on joining to make the CNTs' growth. We term these green extracts as 'green catalyst'. CNT growth in the presence of green catalyst at temperature $\left(575^{\circ} \mathrm{C}\right)$ is
Fig. 7 a EDS report for walnut plant extract. b EDS report for post-CNT growth

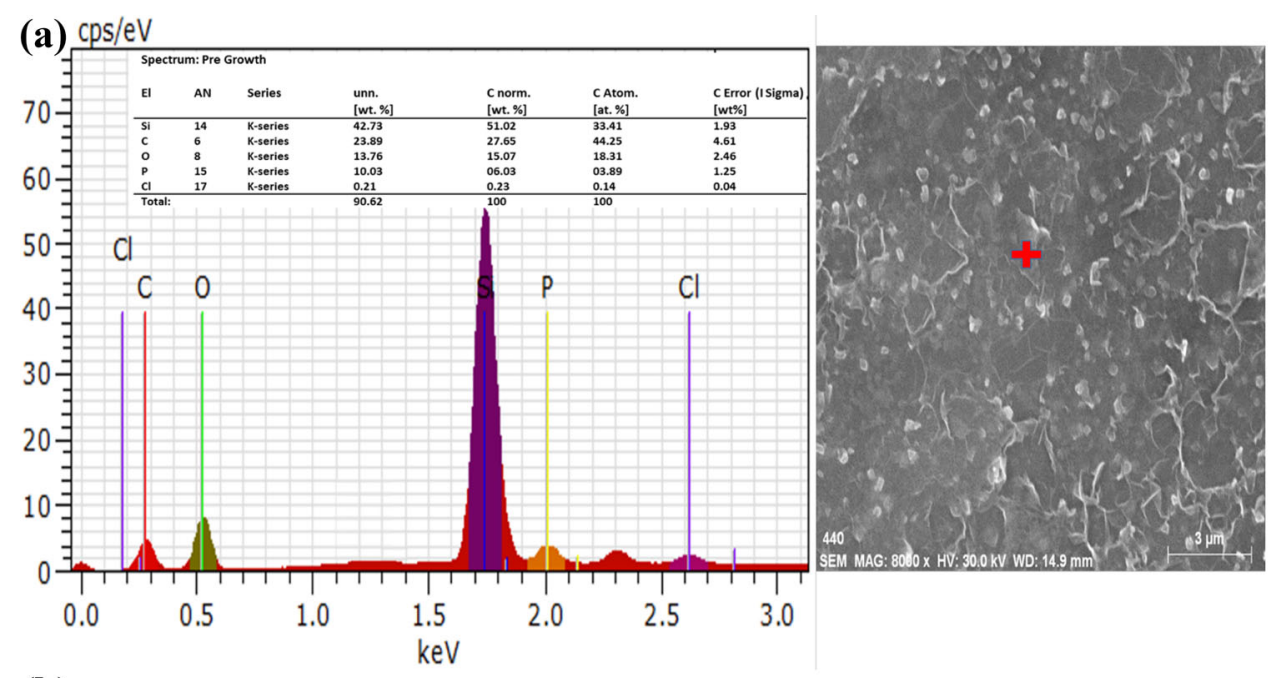

(b)

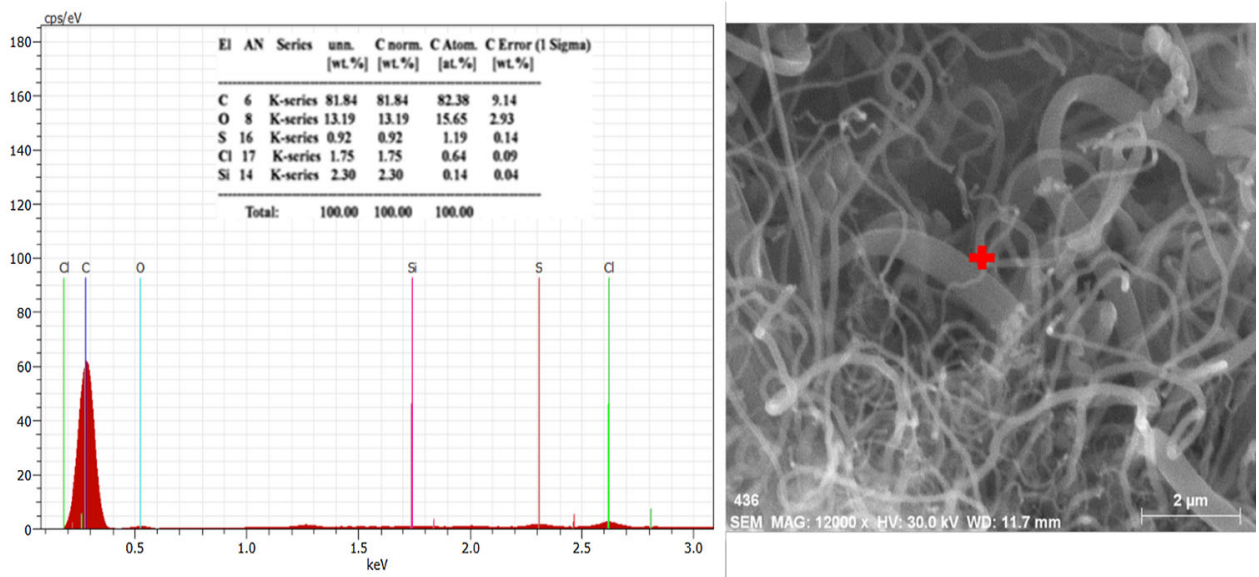



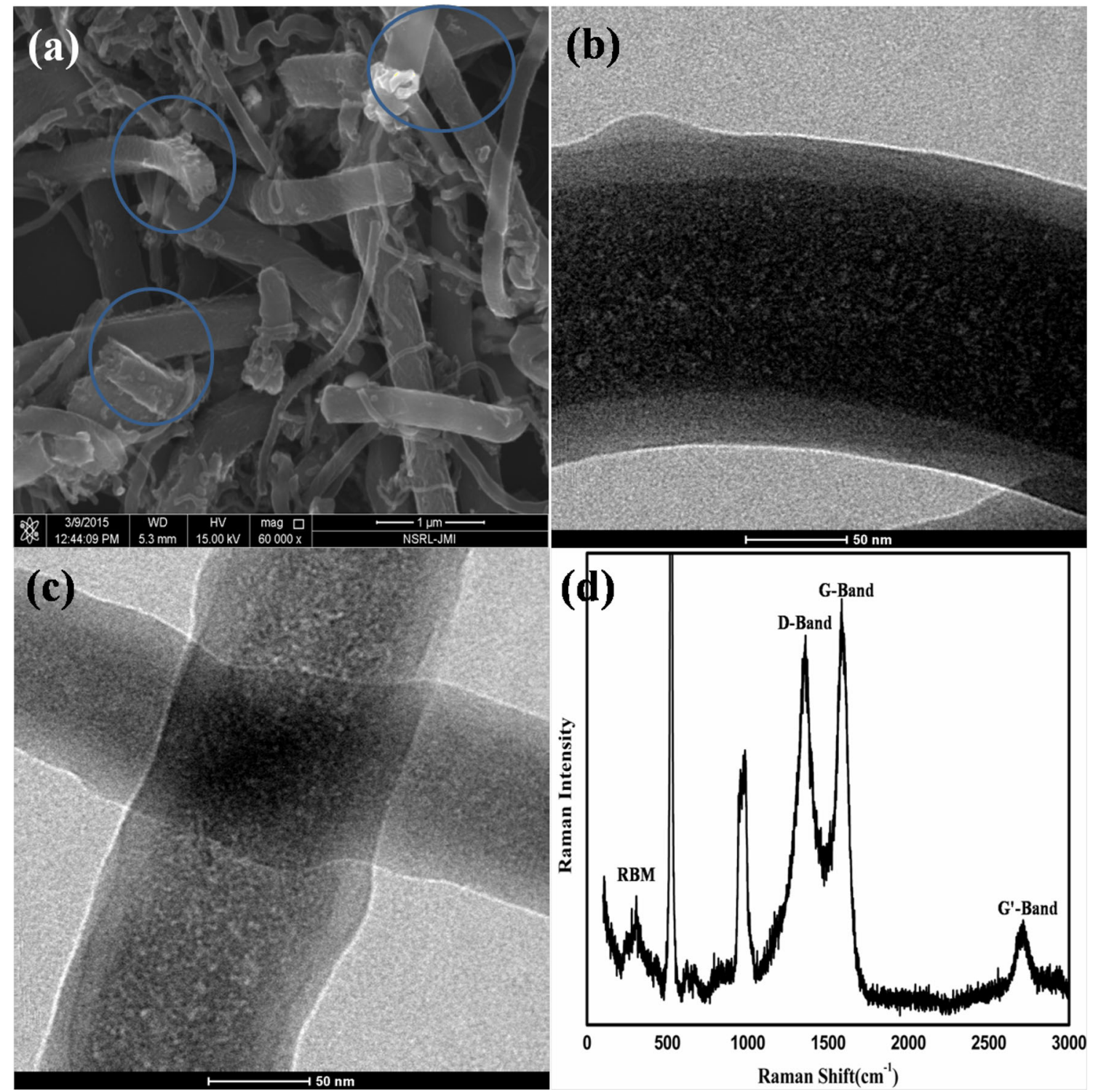

Fig. 8 Analysis of grown CNB at $800{ }^{\circ} \mathrm{C}$ by a FESEM, b, c HRTEM and $\mathbf{d}$ Raman spectroscopy

another unexpected achievement. The normal temperature requirement for MWNTs growth in CVD with catalyst such as transition metal catalysts, or $\mathrm{SiO}_{2}$ or ceramic catalyst, reported in the literature are around $700-1200{ }^{\circ} \mathrm{C}$, required for creating nucleation sites (Tripathi et al. 2014a; Liu et al. 2013; Tripathi et al. 2015; Uthayakumar and Sivasubramanian 2013; Chang and Esei 1998; Zhang et al. 2012; Tripathi et al. 2015; Tripathi and Islam 2017). But in our case activated nucleation sites are already present in activated carbon produced from green catalyst. It may be another possible reason behind low temperature growth. Figure 7 shows the EDX spectra with elemental quantity table for pre- and post-growth of CNTs. In the first case (Fig. 7a), the atomic percent of elements was $33.41 \%$ silicon, $44.25 \%$ carbon, $18.31 \%$ oxygen, $03.89 \%$ phosphors and $0.14 \%$ chlorine. The presence of silicon, carbon, oxygen and chlorine elemental contents confirmed the existence of $\mathrm{SiCH}_{2},-\mathrm{CH}_{2} \mathrm{Cl}, \mathrm{C}=\mathrm{C}$ and $\mathrm{C}-\mathrm{O}$ compounds. No metal element found. In case of post-CNT growth (Fig. 7b), we found $82.38 \%$ for carbon, $15.65 \%$ for oxygen, $0.14 \%$ for silicon, $0.64 \%$ for chlorine and $1.19 \%$ for sulfur, respectively. We observe sharp enhancement in elemental percentage of carbon, and it occurred due to the growth of dense CNTs. The FTIR spectrum for post-CNT growth supports this conclusion.

A trial experiment to grow CNTs with green catalyst at high temperature, i.e., $800{ }^{\circ} \mathrm{C}$ turns out to be an exciting phenomenon, i.e., the formation of $\mathrm{CNBs}$ with hollow rectangular cross-section was observed (shown in Fig. 8). FESEM image (Fig. 8a) shows the formation of a group of 

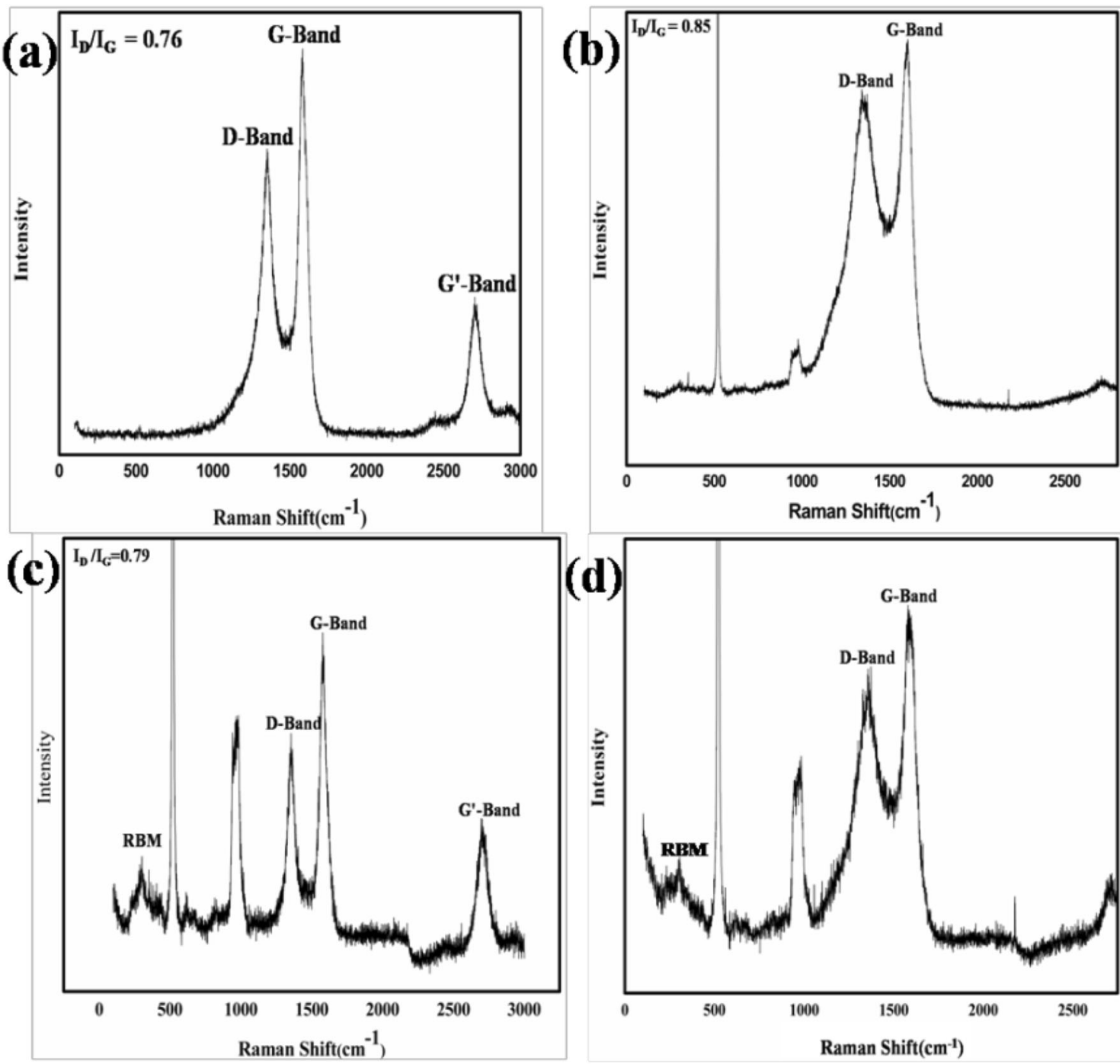

Fig. 9 Raman spectra for grown CNTs with different plant extract a garden grass (Cynodon dactylon), b rose (Rosa), c neem (Azadirachta indica) and d Kaner (Thevetia peruviana)

different types of structure. The interesting one is the formation of CNBs with rectangular cross-section (shown in blue circles) in addition to few slants of very thin tubes. We had examined CNBs by HRTEM (see Fig. 8b, c). It is clearly evident in HRTEM images that CNB-type structures are hollow from inside and built by around $25-\mathrm{nm}$ thick wall. Some random particles were also observed inside the CNBs, and these may be the residue of the green catalyst. Figure 8d shows its Raman spectra for identification of its graphitic structure. The spectra comprises a RBM at 300, D-band at 1340, G-band at 1580 and a peak of G'-band on 2700. The presence of RBM supports the formation of SWNTs (red circled in Fig. 8a). The G-band represents the graphitic structural quality of structure, and its presence proves that carbon atom is the building block of nano-ribbon structure. The intensity ratio between $\mathrm{D}$ and G-band (i.e., $I_{\mathrm{D}} / I_{\mathrm{G}}$ ) is $\sim 0.90$ and it is indicative of having good structural quality. The intensity of G'-band is moderate and it may originate from the CNB whose wall behaves as graphene film. The growth of SWNTs may be interpreted as follows. The general practice is that low temperature CVD $\left(700-900{ }^{\circ} \mathrm{C}\right)$ process yields MWNTs while high temperature CVD $\left(900-1200{ }^{\circ} \mathrm{C}\right)$ process supports SWNTs growth. This shows that SWNTs have higher formation energy (probably due to small diameter; high curvature tolerates high strain energy). This clearly illustrates the reason why MWNTs are easier to develop as compared to SWNTs using above all the hydrocarbons. Another important factor is the size of the catalyst; we believe that at $800{ }^{\circ} \mathrm{C}$ the carbon residue got fragmented into carbon particles of $\mathrm{nm}$ size which favors the formation of SWNTs. The Raman spectra of grown CNTs from other extracts at $800{ }^{\circ} \mathrm{C}$ are shown in Fig. 9. In these spectra, the common feature is the signature of MWNTs growth and 


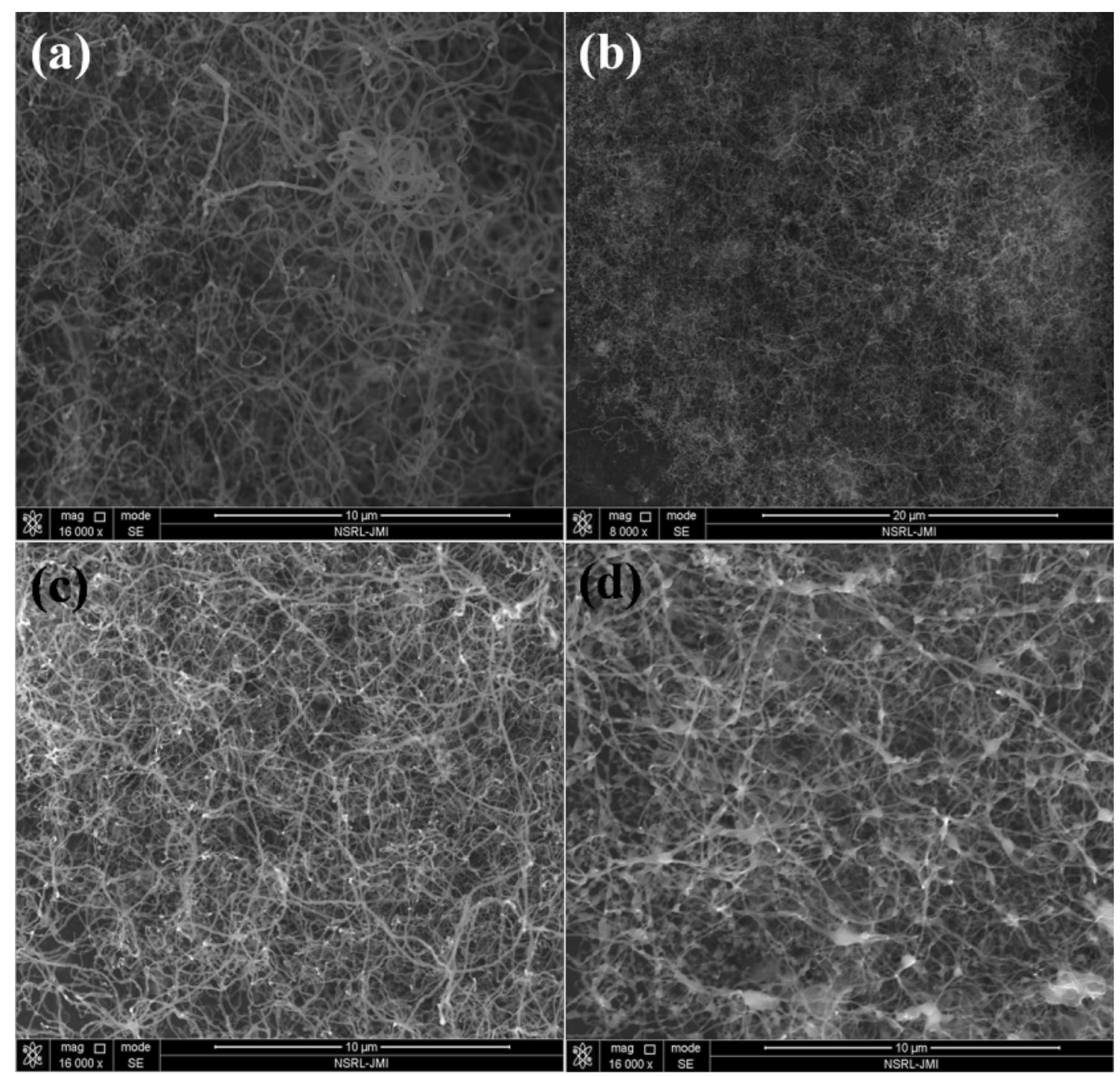

Fig. 10 FESEM images for grown CNTs with different plant extract a garden grass (Cynodon dactylon), b rose (Rosa), c neem (Azadirachta indica) and $\mathbf{d}$ Kaner (Thevetia peruviana)

this is further confirmed from FESEM images shown in Fig. 10. The RBM modes were not observed for other extracts. It may be due to the requirement of different CVD temperature vis-à-vis the walnut case. Further study is needed to find exact CVD temperatures for individual extract.

\section{Conclusion}

An unconventional concept is employed for the synthesis of CNTs, where extract from green plant is used as catalyst. The catalyst is non-metal, and therefore, does not make any impact on human and other living organisms at manufacturing, disposal and application sites. The notable points to mention for such growth are as follows- the growth temperature is low $\left(575^{\circ} \mathrm{C}\right)$, yield is exceptionally high in comparison to other catalysts reported so far and there is no need of complex systems for its synthesis as it can be easily synthesized by simple low cost CVD. Growth of SWNT as well as CNBs is also observed when growth temperature increased to $800{ }^{\circ} \mathrm{C}$, and this observation was confirmed by microscopic and spectroscopic analysis. The experiments were executed for plant extracts taken from garden grass, rose, and neem. MWNTs growth was observed in all the extracts. The formation of CNBs and SWNTs were not observed in other extracts at CVD temperature $800{ }^{\circ} \mathrm{C}$. It requires further study to find out the possible reason behind. 
Open Access This article is distributed under the terms of the Creative Commons Attribution 4.0 International License (http:// creativecommons.org/licenses/by/4.0/), which permits unrestricted use, distribution, and reproduction in any medium, provided you give appropriate credit to the original author(s) and the source, provide a link to the Creative Commons license, and indicate if changes were made.

\section{References}

Bellucci S (2009) Nanoparticles and nanodevices in biological applications, vol 7. Lecture notes in nanoscale science and technology., pp 47-67. doi:10.1038/354056a0

Buzea C, Blandino IIP, Robbie K (2007) Nanomaterials and nanoparticles: sources and toxicity. Biointerphases 2:17-71. doi:10.1116/1.2815690

Chang PH, Esei S, (2003) Fuel science program, effects of carbon surfaces on thermal decomposition of hydrocarbons, Department of Materials Science and Engineering 209 Academic Projects Building, The Pennsylvania State University, University Park, PA 16802, USA. pp 26-31

Iijima S (1991) Helical microtubules of graphitic carbon. Nature 354:56-58. doi:10.1038/354056a0

Liu H, Takagi D, Ohno H, Chiashi S, Chokan T, Homma Y (2008) Growth of single-walled carbon nanotubes from ceramic particles by alcohol chemical vapor deposition. Appl Phys Express 1:014001-014003

Liu B, Ren W, Gao L, Li S, Pei S, Liu C, Jiang C, Cheng HM (2009) Metal-catalyst-free growth of single-walled carbon nanotubes. J Am Chem Soc 131:2082-2083. doi:10.1021/ja8093907

Liu TY, Zhang LL, Yu WJ, Li SS, Hou PX, Cong HT, Liu C, Cheng HM (2013) Growth of double-walled carbon nanotubes from silicon oxide nanoparticles. Carbon 56:167-172. doi:10.1016/j. carbon.2013.01.002

Luc JB, Bruno D (2010) Contamination monitoring and analysis in semiconductor manufacturing. In: Grym J (ed) Semiconductor technologies. InTech, Rijeka, pp 57-78. doi:10.5772/8561

Masarovicova E, Kralova K (2013) Metal nanoparticles and plants. Ecol Chem Eng S 20:9-12. doi:10.2478/eces-2013-0001

Panyala NR, Mendez MP, Havel J (2008) Silver or silver nanoparticles: a hazardous threat to the environment and human health. J Appl Biomed 6:117-129

Ramamurty N, Kannan S (2007) Fourier transform infrared spectroscopic analysis of a plant (Calotropis gigantea linn) from an industrial village, Cuddalore dt, Tamilnadu, India. J. Biophys 17:269-276

Redfern J, Kinninmonth M, Burdass D, Verran J (2014) Using soxhlet ethanol extraction to produce and test plant material (essential oils) for their antimicrobial properties. J Microbiol Biol Educ 15:45-46. doi:10.1128/jmbe.v15i1.656

Sharma P, Gupta N (2016) Model for threshold voltage instability in top-gated nanocrystalline silicon thin film transistor. J Comput Electron 15:666-671. doi:10.1007/s10825-015-0789-7
Sharma P, Tripathi N, Gupta N (2017) Nanocrystalline silicon thin film prepared by e-beam evaporation for display application. J Mater Sci 28:3891-3896. doi:10.1007/s10854-016-6002-3

Silverstein RM, Webster FX, Kiemle DJ (1962) Spectrometric identification of organic compounds. $J$ Chem Educ 39:546-553. doi:10.1021/ed039p546

Singh J, Sahu K, Kuriakose S, Tripathi N, Avasthi DK, Mohapatra S (2017) Synthesis of nanostructured $\mathrm{TiO}_{2}$ thin films with highly enhanced photocatalytic activity by atom beam sputtering. Adv Mater Lett 8:107-113. doi:10.5185/amlett.2017.6432

Tripathi N, Islam SS (2017) A new approach for orientationcontrolled growth of CNTs: an in-depth analysis on the role of oxygen plasma treatment to catalyst. Appl Nanosci 7:125-129. doi:10.1007/s13204-017-0549-Z

Tripathi N, Mishra P, Joshi B, Harsh Islam SS (2014a) Catalyst free, excellent quality and narrow diameter of CNT growth on $\mathrm{Al}_{2} \mathrm{O}_{3}$ by a thermal CVD technique. Phys E 62:43-47. doi:10.1016/j. physe.2014.04.011

Tripathi N, Mishra P, Harsh Islam SS (2014b) Effect of growth temperature on the diameter distribution and yield of carbon nanotubes. In: Jain V, Verma A (eds) Physics of Semiconductor Devices. Environmental Science and Engineering. Cham, Springer, pp 645-646

Tripathi N, Mishra P, Joshi B, Islam SS (2014c) A systematic study on growth of CNTs with liquid chemical salts as catalysts: a fine control on orientation of CNTs. Adv Sci Lett 20:1612-1615. doi:10.1166/asl.2014.5554

Tripathi N, Mishra P, Joshi B, Islam SS (2015a) Precise control over physical characteristics of Carbon nanotubes by differential variation of argon flow rate during chemical vapor deposition processing: a systematic study on growth kinetics. Mater Sci Semicond Process 35:207-215. doi:10.1016/j.mssp.2015.03.014

Tripathi N, Moinuddin MG, Islam SS (2015) Growth of SWNTs using $\mathrm{Cu}\left(\mathrm{NO}_{3}\right)_{2}$ and $\mathrm{CuO}$ : a systematic study on role of oxygen in growth of CNTs INDICON, IEEE, 1-3. doi: 10.1109/ INDICON.2015.7443847

Tripathi N, Mishra P, Harsh H, Islam SS (2015c) Fine-tuning control on CNT diameter distribution, length and density using thermal CVD growth at atmospheric pressure: an in-depth analysis on the role of flow rate and flow duration of acetylene $\left(\mathrm{C}_{2} \mathrm{H}_{2}\right)$ gas. Appl Nanoscience 5:19-28. doi:10.1007/s13204-013-0288-8

Uthayakumar GS, Sivasubramanian A (2013) A novel technique to monitor human vital signs. Int J Biomed Adv Res 4:642-651. doi:10.7439/ijbar.v4i9.471

Zhang C, Zhang X, Huang Z, Huang D, Cheng Q (2012) Adsorption and de-sorption of polycyclic aromatic hydrocarbons on activated carbon. J Environ Anal Toxicol 2:1-6. doi:10.4172/21610525.1000116

\section{Publisher's Note}

Springer Nature remains neutral with regard to jurisdictional claims in published maps and institutional affiliations. 